\title{
Urine screening for a sample of egyptian school students: two centers experience
}

\begin{abstract}
Background: Mass urine screening was a beneficial method to determine the prevalence of kidney disorders and to improve their sequlae. Our work was done to determine the prevalence of silent (hidden) urinary abnormal findings among primary school students in Gharbia and Aswan Governates in Egypt.
\end{abstract}

Subjects and methods: Apparently 2505 healthy primary school students were included in this study. Urine screening was done by urine sampling using the urinary dipstick method.

Results: Sixty six children $(2.6 \%)$ had urinary abnormalities at the first urine screening test and only thirty six $(1.4 \%)$ had urinary abnormalities at the second screening. Of the children who had urinary abnormalities, eighteen $(0.72 \%)$ had isolated hematuria (IH), six $(0.24 \%)$ had isolated proteinuria (IP) and twelve $(0.48 \%)$ had combined hematuria and proteinuria (CHP). Renal biopsy was performed on 12 children 6 [50\%] with CHP, 3[25\%] with IH and 3[25\%] with IP. Post streptococcal acute glomerulonephritis (PSAGN) was identified in $9(50 \%)$, hypercalciuria in $3(16.7 \%)$, urolithiasis in $3(16.7 \%)$ and undetermined cause in $3(16.7 \%)$ of the IH children. Three $(50 \%)$ of the IP children had orthostatic proteinuria and the other $3(50 \%)$ had focal segmental glomerulosclerosis. The pattern of kidney diseases in CHP children was PSAGN in $6(50 \%)$, diffuse mesangial proliferation in $3(25 \%)$ and IgA nephropathy in $3(25 \%)$.

Conclusions: Asymptomatic urinary abnormalities were reported in a few number of primary school students in Gharbia and Aswan Governates in Egypt and PSAGN was the main etiology for these urinary findings. Nine $(0.36 \%)$ of studied subjects had evidence of chronic kidney disease. This study clarified the significance of comparing the cost-benefit ratio for the application of the national program of the urine screening among school children.

Keywords: urine screening, school students
Volume 2 Issue I - 2018

\author{
Mohamed Abdelaziz El-Gamasy,' Ahmed \\ Ragab Fakhreldin ${ }^{2}$ \\ 'Lecturer of Pediatrics, Faculty of Medicine, Tanta University, \\ Egypt \\ ${ }^{2}$ Assistant professor of Pediatrics, Aswan University, Egypt
}

Correspondence: Mohamed Abdelaziz El Gamasy, Assistant Professor of Pediatrics, Faculty of Medicine, Tanta University, Egypt, Tel 201208I36076,Email mgamsy@gmail.com

Received: November 20, 2017 | Published: February 06, 2018
Abbreviations: RBCs, red blood cells; CHP, combination of both hematuria and proteinuria; PSAGN, post streptococcal acute glomerulonephritis; IH, isolated hematuria; IP, isolated proteinuria; DMP, diffuse mesangial proliferation; SLE, systemic lupus erytheromatosis

\section{Introduction}

Urinalysis as a simple, non invasive and inexpensive laboratory test remains to be the cornerstone tool in the assessment of the urinary system. It can be easily used for screening of kidney diseases. Previously many screening programs using urinalysis have been carried out using reagent strips testing, and their effectiveness in evaluating kidney disorders with relatively low costs. ${ }^{1,2}$ Mass urine screening test enable general pediatrician to detect the prevalence of disorders of urinary system ${ }^{3}$ aiming to improve the sequlae in this vulnerable group of population. ${ }^{4}$ Since the prevalence of kidney disorders in most of Arabian countries like Egypt still not known, this work was done to screen the urinary samples of primary school students in Gharbia and Aswan Governorates in Egypt by using dipstick method aiming early diagnosis of asymptomatic urinary abnormalities and their underlying predisposing factors mainly renal disorders.

\section{Subjects and methods}

This cross sectional prospective study was done in the period from
November 2015 to November 2017 on 2505 primary school students from two different governates; Gharbia Governate which is located in the middle of Delta region of Egypt and Aswan Governorate in Upper Egypt. The population of primary school students in Gharbia and Aswan Governorates at the start of this study was about one third million students. Two thirds live in rural areas and more than half of them are males. The subjects were selected in a random method from 48 primary schools: $33(68.8 \%)$ in rural areas and $15(31.2 \%)$ in urban areas. Of the 2505 students, 1305 (52.1\%) were from rural areas whereas $1200(47.9 \%)$ from urban areas. Among them, 1365 $(54.5 \%)$ were boys and $1140(45.5 \%)$ girls. Their ages ranged from 6 to 13 years. None of the children had clinical evidence of kidney and or systemic diseases.

\section{Ethical issues}

I. The research followed the tenets of the Declaration of Helsinki.

II. Obtaining informed written or oral consents from the students' parents or their school managers.

III. The study was carried out after approval from by the Research Ethical Committees of Tanta and Aswan Faculties of Medicine.

All participants in this study were instructed to collect a sample of urine by voiding a clean catch mid stream urine specimen into a $200 \mathrm{ml}$ vessel, which was sent to a laboratory of clinical pathology departments 
of Tanta University Hospital (TUH) and Aswan University Hospital (AUH). A urinary dipstick test (Multistix, Bayer Diagnostics, Miles Inc., USA) was performed on the collected urine specimens by a well skilled laboratory technicians at $\mathrm{TUH}$, with reagent strip designed to react progressively producing color changes in given intervals. The results were decided by visual comparison of the test strip with a color chart provided on the bottle label. Urine samples were then prepared for microscopic examination by centrifuging $10 \mathrm{ml}$ of well-mixed urine at $1500 \mathrm{~g}$ for 5 minutes in a graduated plastic conical centrifuge tube. Most of the supernatant was poured off by inversion of the tube and the sediment was thoroughly re-suspended in the remaining supernatant. One drop of this suspension was placed on a glass slide, cover-slipped, and examined by subdued bright-field illumination at $\times 100$ and $\times 400$ under a light microscope. For the included children, Urine analysis was done three times before recording the data that make good validation for the results of our research.

\section{Abnormal urinary findings were defined as the following:}

a. A red blood cell (RBCs) counts of five or more per high power field (HPF) as (IH).

b. One or more plus protein in urine sample (IP).

c. Combination of both hematuria and proteinuria (CHP)

Children who were tested and reported positive abnormal urinary findings were received a second urinary screening testing after10-15 days from the first screen. The studied children who showed persistent urinary abnormalities were subjected to further assessment. Percutenous ultrasonography guided kidney biopsy was done for included children who had hematuria and/or proteinuria which persisted for more than 6 months. Specimens of renal biopsy were examined by light microscopy, immunofluorescence and in some situations by electron microscopy. ${ }^{5}$ The renal lesions were histopathologically interpretated according to the World Health Organization (WHO) Classification. ${ }^{6}$ Diagnosis of Post streptococcal acute glomerulonephritis (PSAGN) in our study depended on presence on hematuria with or without proteinuria, low complement $3(\mathrm{C} 3)$, normal complement $4(\mathrm{C} 4)$ with

Table I Demographic Characteristics of Studied Children. evidence of recent streptococcal infection of throat or skin. ${ }^{7}$ Diagnosis of Hypercalciuria was considered when urinary calcium to Urinary creatinine ratio $\geq 0.2$.

\section{Statistical analysis}

Statistical analysis was performed by using statistical package for social science (SPSS) version 11. Qualitative data were expressed as numbers and percentages (\%). Comparison between data was performed by using the Chi-square test $\left(\mathrm{X}^{2}\right)$. A $P$ value more than 0.05 was considered statistically non significant. A $P$ value less than 0.05 was considered statistically significant.?

\section{Results}

At the first urine screening of our subjects, 66 children (2.6\%) had urinary abnormalities, however only 36(1.4\%) of them had urinary abnormalities at the second urine screening. Table 1 summarized demographic data of the studied students. No statistically significant difference was observed in the prevalence of urinary abnormalities between males and females ( $p>0.05$ ). As regard age, no statistically significant difference was observed in the prevalence of urinary abnormalities between younger and older than 10 years $(\mathrm{p}>0.05)$, As regard residence of included children, there was no statistically significant difference in the prevalence of urinary abnormalities between children living in rural and urban regions $(\mathrm{p}>0.05)$, Of the children with abnormal urinary screening test $18(0.72 \%)$ had isolated hematuria (IH), $6(0.24 \%)$ had isolated proteinuria (IP), and $12(0.48 \%)$ had combined hematuria and proteinuria (CHP). Renal biopsy was performed on $12(0.48 \%)$ children (6 with CHP, 3 with $\mathrm{IH}$, and 3 with IP). No abnormalities were detected in three $(0.12 \%)$ children whereas focal segmental glomerulosclerosis (FSGS), diffuse mesangial proliferation (DMP) and IgA nephropathy (IgAN) were detected in the other $9(0.36)$ children equally. Table 2 reported results of abnormal urinary findings as follow: PSAGN was diagnosed in $9(50 \%)$ of the children with $\mathrm{IH}$, hypercalciuria in $3(16.7 \%)$ and renal stone in $3(16.7 \%)$, and no abnormality in $3(16.7 \%)$. Three $(50 \%)$ of the six IP children had orthostatic proteinuria and the other half had FSGS. In the twelve CHP children, $6(50 \%)$ had PSAGN, 3(25\%) had IgAN and 3(25\%) had DMP.

\begin{tabular}{|c|c|c|c|c|}
\hline \multicolumn{5}{|l|}{ Urinary abnormalities } \\
\hline & $\begin{array}{l}\text { Positive } \\
(\mathrm{No}=36)\end{array}$ & $\begin{array}{l}\text { Negative } \\
(\mathrm{No}=2469)\end{array}$ & $\begin{array}{l}\text { Total } \\
(\mathrm{No}=2505)\end{array}$ & $P$ value \\
\hline Sex Distribution: & 15 (4I.7\%) & $1350(54.7 \%)$ & $1365(54.5 \%)$ & $>0.05$ \\
\hline \multicolumn{5}{|l|}{ Males: No (\%) } \\
\hline Females: No (\%) & $2 \mathrm{I}(58.3 \%)$ & $1119(45.3 \%)$ & $1140(45.5 \%)$ & $>0.05$ \\
\hline Age At Enrollment (Years): & 15 (4I.7\%) & $1338(54.2 \%)$ & $1353(54 \%)$ & $>0.05$ \\
\hline \multicolumn{5}{|l|}{ Below 10 years } \\
\hline Above 10 years & $21(58.3 \%)$ & || $3 \mid(45.8 \%)$ & $1152(46 \%)$ & $>0.05$ \\
\hline Residence: & $18(50 \%)$ & $1287(52.1 \%)$ & $1305(52.1 \%)$ & $>0.05$ \\
\hline \multicolumn{5}{|l|}{ Rural : } \\
\hline Urban: & $18(50 \%)$ & | $182(47.9 \%)$ & $1200(47.9 \%)$ & $>0.05$ \\
\hline
\end{tabular}

$\mathrm{X}^{2}$ (Chi square test )was used for comparing between the two studied children groups with positive and those with negative urinary abnormalities' values were $>0.05$ meaning that there were no statistically significant differences between the 2 studied groups. 
Table 2 The Patterns of Renal Diseases in School Children with Persistent Urinary Abnormalities.

\begin{tabular}{|c|c|c|c|c|c|c|}
\hline & \multicolumn{2}{|c|}{$\begin{array}{l}\text { Intermittent hematuria } \\
(\mathrm{N}=18)(0.72 \%)\end{array}$} & \multicolumn{2}{|c|}{$\begin{array}{l}\text { Intermittent proteinuria } \\
(\mathrm{N}=6)(0.24 \%)\end{array}$} & \multicolumn{2}{|c|}{$\begin{array}{l}\text { Combined hematuria and } \\
\text { proteinuria }(N=12)(0.48 \%)\end{array}$} \\
\hline & No & $\%$ & No & $\%$ & No & $\%$ \\
\hline Hypercalcuria & 3 & 16.7 & 0 & 0 & 0 & 0 \\
\hline Urolithiasis & 3 & 16.7 & 0 & 0 & 0 & 0 \\
\hline $\begin{array}{l}\text { Acute post streptococcal } \\
\text { Glomerulonephritis }\end{array}$ & 9 & 50 & 0 & 0 & 6 & 50 \\
\hline FSGS & 0 & 0 & 3 & 50 & 0 & 0 \\
\hline DMP & 0 & 0 & 0 & 0 & 3 & 25 \\
\hline IgA nephropathy & 0 & 0 & 0 & 0 & 3 & 25 \\
\hline Orthostatic proteinuria & 0 & 0 & 3 & 50 & 0 & 0 \\
\hline Undetermined causes & 3 & 16.7 & 0 & 0 & 0 & 0 \\
\hline
\end{tabular}

IH, Isolated Hematuria; IP, Isolated Proteinuria; CHP, Combined Hematuria and Proteinuria; FSGS, Focal Segmental Glomerulosclerosis; DMP, Diffuse Mesangial Proliferation; IgAN, IgA Nephropathy

$\mathrm{X}^{2}$ (Chi square test) was used for comparing between the three studied children groups with intermittent hematuria, those with intermittent proteinuria and those with combined hematuria and proteinuria. $\mathrm{P}$ values were $>0.05$ meaning that there were no statistically significant differences between the 3 studied groups.

\section{Discussion}

There were few publications on the prevalence of silent urinary abnormal findings among school children in Arabian countries. Only $2.6 \%$ of the studied urinary specimens had abnormal findings at the first screen test, and these urinary findings had persisted in $1.4 \%$ at the second screen urine testing. Our results were less than that reported previously by ${ }^{10}$ who had screened more than fourteen thousand south American students at Bolivia (more than three quarter of them were under the age of fifteen years) and they concluded that abnormal urine findings were reported in about one third of their subjects at the first urinary screen test and in only one thousands and nineteen students (about seven percent of studied subjects) at the second screen test. Our results were more than that reported previously by who screened more than forty five thousand Asian primary school students from Malaysia study, for and they reported that only two percent of their screened subjects had positive findings indicating proteinuria and or hematuria and added that only $0.1 \%$ of their subjects were reported to be positive for proteinuria and or hematuria on further follow up urine screening. ${ }^{11}$ Other Asian previously published studies had showed abnormal urinary findings on urine screening of their studied subjects in only $0.6 \%$ in Japan, ${ }^{12}$ and only $0.3 \%$ in Taiwan, ${ }^{4}$ The only African study done in Nigeria and has reported $5.25 \%$ of their studied school children to have urinary abnormalities on screening. ${ }^{13}$

In this work, nighter's age nor sex had an effect on the prevalence of urinary abnormalities .Also in our study socioeconomic standard had no impact on the prevalence of urinary abnormalities. Among the affected subjects in our study, the ratio of boys to girls was $0.71: 1$. Our results were in accordance with ${ }^{14}$ who reported that the prevalence of abnormal urine findings was not affected by age or gender. Our results were also in accordance with ${ }^{14}$ who found that a boys to girls ratio of 0.9:1 in their studied Korean subjects and with ${ }^{10}$ who reported that abnormal microscopic urinary findings were more prevalent in their studied African females than in males but our results were not in accordance with Lin CY, who reported a ratio of male to female to be 1.1:1 in their studied Taiwan subjects. ${ }^{15}$ In this work, IH was reported in $0.72 \%$ of the studied subjects while IP and CHP were reported in $0.24 \%$ and $0.48 \%$ respectively. Our results were in agreement with ${ }^{8}$ who concluded that IP was the commonest abnormal urinary findings $(0.12 \%)$ followed by IH and CHP on screening primary school Asian students in their study in Malaysia.

Previously published Asian articles reported that prevalence of IH and IP among elementary school students in Japan ${ }^{16}$ and in Korea ${ }^{17}$ was $0.5 \%$ and $0.05 \%$, and $0.6 \%$ and $0.5 \%$ respectively. Our results were not in agreement with Yap HK et al who reported that. On the first urinary screening of their studied twelve-year-old subjects in Singapore, IH, IP and CHP were positive in $6.8 \%, 1.2 \%$ and $2.3 \%$ of the studied subjects respectively. ${ }^{18}$ In our study, assessment of students with persistent urinary abnormalities reported that glomerulonephritis (GN) was the commonest involved etiology in this work. Of the 36 subjects with persistent urinary abnormalities, 15 (41.7\%) had evidence of GN. Hypercalciuria, urolithiasis and orthostatic proteinuria were the other etiologies. Undetermined etiology was detected in three subjects who had nighters family history of urinary abnormalities nor abnormal electron microscopic histopathology. Previous studies had confirmed that GN was the main etiology of abnormal urinary findings. ${ }^{4,19}$ Our results were not in accordance with ${ }^{20}$ who reported that undetermined etiology was reported in 80 $\%$ of their studied subjects with microscopic hematuria and the most common cause of the microscopic hematuria was hypercalciuria $(16 \%$ of their subjects).

Similarly, Our results were not in accordance with ${ }^{21}$ who reported that more than half of their studied subjects who were screened and had silent urinary abnormalities had undetermined cause, but organic renal disorders and hypercalciuria were accounted for 15 $\%$ and $14 \%$ of their studied subjects respectively. PSAGN was the most common form of GN encountered in this work. Three children had FSGS, 3 had DMP and 3 had IgAN. In other studies, systemic lupus erytheromatosis (SLE) was the most common cause of GN as diagnosed by a mass urine screening for primary school students. ${ }^{15}$ Also, IgAN was the main cause of GN in Japan ${ }^{22}$ and Korea. ${ }^{4}$ PSAGN 
was highly prevalent in Arab world especially Egypt as group A of $\beta$-hemolytic streptococcal bacteria is still endemic. Ultrasolnography guided renal biopsy was done in 12 children in this study (6 with CHP, 3 with IP and 3 with IH). No histopathological abnormality was reported in the children with IH but FSGS, DMP and IgAN were diagnosed in the others.

Asymptomatic hematuria is known as a common disorder in pediatric age and it is likely to have a good prognostic sequlae ${ }^{18}$ Extensive assessment is mostly not recommended in such patients that can generally be followed up in outpatient pediatric nephrology clinic after a meticulous assessment for exclusion of urinary disorders mainly urinary tract infection, hypercalciuria, PSAGN, and congenital anomalies of kidney and or urinary tract. ${ }^{23,24}$ The most common etiologies of persistent non-orthostatic, pathological proteinuria in pediatrics were FSGS, IgAN and membranoproliferative GN. ${ }^{25}$ Kidney biopsies in pediatric patients with asymptomatic urinary abnormalities revealed more histopathological abnormalities in subjects with CHP than in those with IH or IP. ${ }^{4-26}$ Hematuria coexisting with proteinuria was well correlated with the severity of morphological changes of glomerular structure of kidneys in the pediatric patients with asymptomatic proteinuria and hematuria. ${ }^{27,28}$

\section{Conclusion}

In conclusion, asymptomatic urinary abnormalities were present in a considerable percentage among sample of primary school students in famous Arab country like Egypt, and PSAGN was the main etiology for these abnormal findings. In this study, nine patients showed evidence of chronic kidney disease. This study raised a alarm about the cost-benefit ratio for the national implementation of the urinary screening program for school students.

\section{Acknowledgements}

To our colleagues at departments of Clinical pathology and Diagnostic Radiology of Faculties of Medicine of Tanta and Aswan Universities and to the parents of included subjects for cooperation.

\section{Conflict of interest}

The author declares no conflict of interest.

\section{References}

1. Marquette GP, Dillard T, Bietla S, et al. The validity of the leukocyte esterase reagent test strip in detecting significant leukocyturia. Am J Obstet Gynecol. 1985;153(8):888-889.

2. Arm JP, Peile EB, Rainford DJ, et al. Significance of dipstick hematuria. Correlation with microscopy of the urine. Br J Urol. 1986;58(2-4):211217.

3. Kitagawa T. Lessons learned from the Japanese nephritis screening study. Pediatr Nephrol. 1988;2(2):256-263.

4. Park YH, Choi JY, Chung HS, et al. Hematuria and proteinuria in a mass school urine screening test. Pediatr Nephrol. 2005;20(8):1126-1130.

5. Chen WP, Lin CY, Hsu HC, et al. Childhood nephritic syndrome and heavy proteinuria in Taiwan: a retrospective clinicopathologic study. Child Nephrol Urol. 1989;9:57-64.

6. Churg J, Sobin H. Renal disease. Classification and atlas of glomerular disease. In: Jacob Churg, Jay Bernstein, editors. Igaku-Soin, Japan; 1982. p. $127-131$
7. Speers DJ, Levy A, Gichamo A, et al. M Protein gene (emm type) analysis of group A Streptococcus isolates recovered during acute glomerulonephritis outbreak in northern western Australia. Pathology. 2017;49(7):765-769.

8. Egshatyan LV, Mokrysheva NG. Calciuria as a metabolic marker for various conditions and diseases. Urologia. 2017;5:132-138.

9. Kirkpatrick LA, Feeney BC. A simple guide to IBM SPSS statistics for version 20.0. Belmont Calif, USA; 2013.

10. Plata R, Silva C, Yahuita J, et al. The first clinical and epidemiological program on renal disease in Bolivia: a model for prevention and early diagnosis of renal disease in the developing countries. Nephrol Dial Transplant. 1998;13(12):3024-3036.

11. Zainal D, Baba A, Mustaffa BE. Screening proteinuria and hematuria in Malaysian children. Southeast Asian J Trop Med Public Health 1995;22:785-788.

12. Murakami M, Yamamoto H, Ueda $\mathrm{Y}$, et al. Urinary screening of elementary and junior high-school children over a 13-year period in Tokyo. Pediatr Nephrol. 1991;5(1):50-53.

13. Oviasu E, Oviasu SV. Urinary abnormalities in asymptomatic adolescent Nigerians. West Afr J Med. 1994;13(3):152-155.

14. AU-Vehaskari VM, Rapola J, Koskimies O, et al. Microscopic hematuria in school children: epidemiology and clinicopathologic evaluation. $J$ Pediatr. 1979;95(5):676-684.

15. Lin CY, Hsieh CC, Chen WP, et al. The underlying diseases and followup in Taiwanese children screening by urinalysis. Pediatr Nephrol. 2001;16(3):232-237.

16. Murakami M, Yamamoto $\mathrm{H}$, Ueda $\mathrm{Y}$, et al. Urinary screening of elementary and junior high-school children over a 13-year period in Tokyo. Pediatr Nephrol. 1991;5(1):50-53.

17. Ministry of Education and Human Resources Development. Educational Statistics System. Sum of results in laboratory tests for school children. Statistical Yearbook of the Korean Ministry of Education and Human Resources Development Korean Education and Research Information Centre, Soul, Korea; 2002. 1:1-24.

18. Yap HK, Quek CM, Shen Q, et al. Role of urinary screening programmes in children in the prevention of chronic kidney disease. Ann Acad Med Singapore. 2005;34(1):3-7.

19. Cho BS, Kim SD, Choi YM, et al. School urinalysis screening in Korea: prevalence of chronic renal disease. Pediatr Nephrol. 2001;16(12):11261128.

20. Bergstein J, Leiser J, Andreoli S. The clinical significance of asymptomatic gross and microscopic hematuria in children. Arch Pediatr Adolesc Med. 2005;159:353-359.

21. Chander J, Gomez Marin O, del Pozo R, et al. Role of routine urinalysis in asymptomatic pediatric patients. Clin Pediatr (Phila). 2005;44:43-48.

22. Hisano S, Ueda K. Asymptomatic hematuria and proteinuria: renal pathology and clinical outcome in 54 children. Pediatr Nephrol. 1989;3(3):229-234.

23. Vehaskari VM, Rapola J. Isolated proteinuria: analysis of a school-age population. J Pediatr. 1982;101(5):661-668.

24. Auwardt R, Savige J, Wilson D. A comparison of the clinical and laboratory features of thin basement membrane disease (TBMD) and IgA glomerulonephritis (IgA GN). Clin Nephrol. 1982;52(1):1-4.

25. Yoshikawa N, Kitagawa K, Ohta K, et al. Asymptomatic constant isolated proteinuria in children. J Pediatr. 1991;119(3):375-379. 
26. Murakamia M, Ueda Y, Murakami K. Management of children with chronic diseases at school-renal disease. Acta Paediatr Jpn Overseas Ed. 1985;27:406-414.

27. Miller PFW, Speirs NI, Apricio SR, et al. Long-term prognosis of recurrent hematuria. Arch Dis Child. 1985;60:420-425.
28. Vehaskari VM, Rapola J. Isolated proteinuria: analysis of school-age population. J Pediatr. 1982;101(5):661-668. 